\title{
The Impact of Introducing a Low Traffic Neighbourhood on Street Crime, in Waltham Forest, London
}

\author{
Anna Goodman ${ }^{1}$ (1), Rachel Aldred ${ }^{2}$ (1) \\ ${ }^{1}$ London School of Hygiene and Tropical Medicine, ${ }^{2}$ University of Westminster \\ Keywords: low traffic neighbourhood, modal filter, permability, crime \\ 10.32866/001c.19414
}

Findings

\begin{abstract}
Using police data, 2012-2019, we examine the impact on street crime of introducing low traffic neighbourhoods in Waltham Forest, London. Overall, the introduction of a low traffic neighbourhood was associated with a $10 \%$ decrease in total street crime (95\% confidence interval $7 \%$ to $13 \%$ ), and this effect increased with a longer duration since implementation ( $18 \%$ decrease after 3 years). An even larger reduction was observed for violence and sexual offences, the most serious subcategory of crime. The only subcategory of crime that increased significantly was bicycle theft, plausibly largely reflecting increased cycling levels. There was no indication of displacement of any crime subcategory into adjacent areas.
\end{abstract}

\section{QUESTIONS}

'Low Traffic Neighbourhoods' (LTNs) are area-based interventions that remove through motor traffic from residential streets, typically via modal filters that restrict motor vehicles while leaving streets 'permeable' to pedestrians and cyclists. In 2020, LTNs were widely implemented across the UK.

The impact of street permeability on crime has long been debated (Cozens and Love 2009). This debate often focuses on contrasts between fully permeable urban grids versus fully impermeable cul-de-sacs. We are aware of only one study examining the impact of introducing area-wide filtered permeability measures, and this reported a reduction in crime, particularly violent crime (Newman 1996). This relative lack of research attention is unfortunate as it seems possible that LTNs could unite some of the hypothesised benefits of high permeability (e.g. increasing walking and social interaction, which may deter crime by having more 'eyes on the street' (Jacobs [1961] 2000)) and low permeability (e.g. giving residents a greater sense of ownership of their area, reducing ease of access [by car] for potential criminals (Newman 1973)). On the other hand, LTN critics have raised concerns that a reduction in motor vehicle throughput might increase crime, although we know of no literature supporting this.

Since 2015, the London Borough of Waltham Forest has implemented multiple LTNs, using physical barriers and lockable bollards (see Figure 1). We examine how this affected street crime inside LTNs and in adjacent areas. 


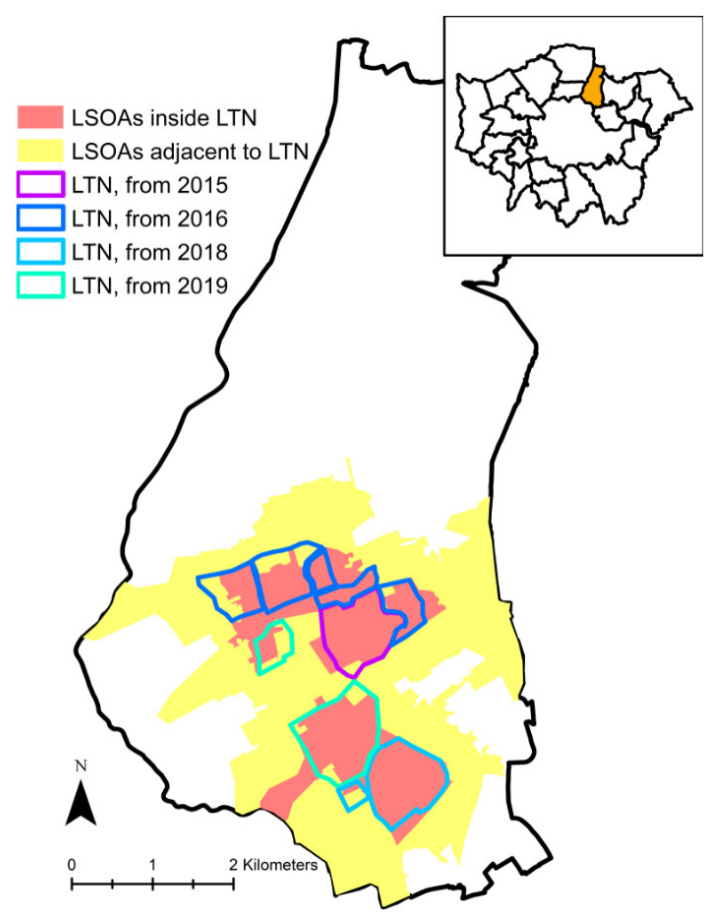

Figure 1: Areas inside LTNs and adjacent to LTNs in the London Borough of Waltham Forest

LSOA = Lower super output area, LTN = low traffic neighbourhood. The main map shows the London Borough of Waltham Forest, the LTNs that were launched 2015-2019, and the LSOAs that we considered inside and adjacent to these LTNs. The inset map shows Waltham Forest within Outer London.

\section{METHODS}

Between January 2012 and December 2019, the London Metropolitan Police recorded 4,411,702 street crimes in Outer London and assigned each to the nearest of $41,457^{\text {' }}$ anonymous map points'. ${ }^{1}$ We aggregated these map points to Lower Super Output Areas (LSOAs) which are administrative areas containing around 1500 inhabitants. We also aggregated crimes by calendar quarter. This generated 3098 Outer London LSOAs $* 8$ years $* 4$ quarters $=99,136$ street crime counts.

We identified whether each LSOA in each calendar quarter was a) inside a Waltham Forest LTN, or b) adjacent to an LTN, or c) neither (our control group) (Figure 1). We defined 'inside' as at least 50\% of the LSOA's buildings being inside the intervention area. We defined 'adjacent' as having an LSOA boundary within $250 \mathrm{~m}$ of an LTN boundary, to explore whether crimes were displaced to other local areas. The two intervention categories were mutually exclusive: areas marked red on Figure 1 moved directly from 'control' to 'inside', never being considered 'adjacent' in the interim. In the 2011 Census, the demographic and socio-economic characteristics of residents in areas that ever received LTNs were very similar to their neighbours in adjacent areas (see Supplemental Information). 
Table 1: Number of street crimes 2012-2019, by study area

\begin{tabular}{|l|c|c|c|c|}
\hline & $\begin{array}{c}\text { Areas ever inside } \\
\text { LTNs }\end{array}$ & $\begin{array}{c}\text { Areas ever adjacent to } \\
\text { LTNs }\end{array}$ & $\begin{array}{c}\text { Other parts of Outer } \\
\text { London }\end{array}$ & Total \\
\hline All street crime & 59,086 & 79,634 & $4,272,982$ & $4,411,702$ \\
\hline Violence and sexual offences & 11,060 & 16,141 & 833,743 & 860,944 \\
Robbery & 1,940 & 2,459 & 111,632 & 116,031 \\
Public order and possession of & 2,647 & 3,383 & 183,988 & 190,018 \\
weapons & 2,906 & 3,676 & 154,881 & 161,463 \\
Drugs & 3,341 & 4,599 & 274,994 & 282,934 \\
Criminal damage and arson & 3,818 & 5,327 & 365,169 & 374,314 \\
Burglary & 4,948 & 7,985 & 459,749 & 472,682 \\
Vehicle crime & 659 & 1,139 & 41,296 & 43,094 \\
Bicycle theft [from July 2013] & 10,888 & 11,779 & 680,492 & 703,159 \\
Other theft and shoplifting & 16,058 & 21,831 & $1,095,662$ & $1,133,551$ \\
Anti-social behaviour & 395 & 544 & 35,905 & 36,844 \\
Other street crime [from July & & & & \\
2013] & \multicolumn{3}{|c|}{} \\
\hline
\end{tabular}

LTN $=$ low traffic neighbourhood.

Our primary outcome was the total number of street crimes. As secondary outcomes, we analysed separately 11 available sub-categories of crime (Table 1). The exposure of interest was being inside an LTN or an adjacent area, relative to the no intervention control group. For our primary outcome, we also present analyses subdivided by duration of time in an LTN or adjacent area. We fit multilevel negative binomial regression models, with the number of street crimes as the outcome; with LTN status, year and calendar quarter as fixed effect predictors; and with random intercepts for LSOA.

For our primary outcome, we fit an equivalent multilevel linear regression model predicting the logged number of street crimes per capita. ${ }^{2}$ We converted the regression coefficients ( $\beta s)$ to percentage change estimates using the formula $[\exp (\beta)-1]^{*} 100 .^{3}$

\section{FINDINGS}

From 2016 onwards, street crime showed a more favourable trajectory in areas that progressively became LTNs than in other parts of Waltham Forest or Outer London (Figure 2). By contrast the trends were very similar from 2012-2015, indicating that the subsequent street crime reduction was not simply a continuation of a pre-existing favourable trend.

\footnotetext{
2 We follow the English Indices of Multiple Deprivation in defining 'per capita' in terms of the 'population at risk', namely a) the mid-year resident population for the year in question as estimated by the Office for National Statistics plus b) the number of non-resident workers measured in the 2011 Census.

3 We did not do this for subcategories of crime as many subcategories had frequent zero counts, which cannot readily be log transformed.
} 


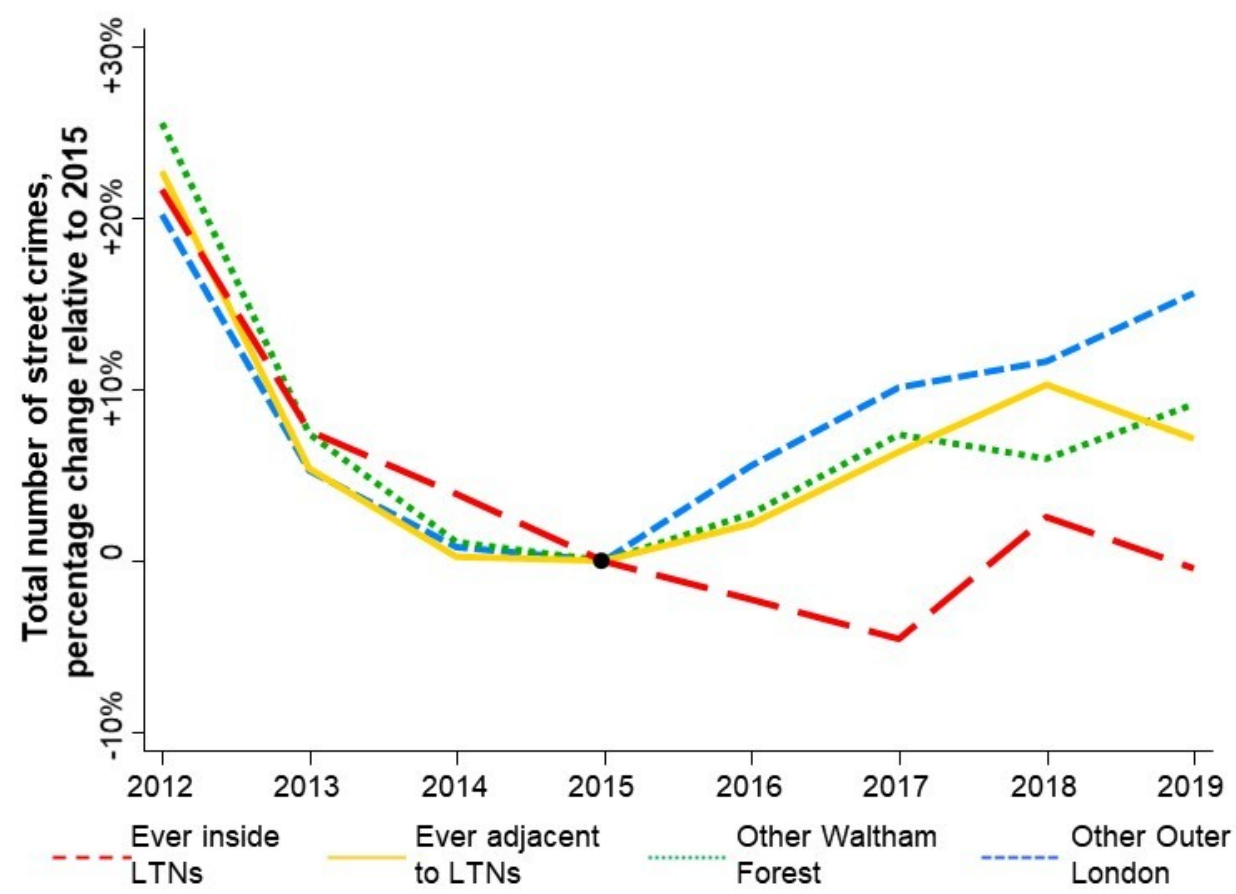

Figure 2: Percentage change in street crime from 2012 to 2019, by area type

LTNs = low traffic neighbourhoods. Note that to allow meaningful comparison across time, this Figure compares identical areas each year. The group 'ever inside LTNs' is that which is shown in red in Figure 1, i.e. where LTNs were progressively introduced from 2015-2019. In regression analyses and in Figure 3 these 'ever inside LTN' areas are only reclassified from the 'no intervention' control group to the 'LTN' group once the LTN is actually implemented. The equivalent also applies to areas adjacent to LTNs.

Relative to the no intervention control group, being in an LTN was associated with an incidence rate ratio of 0.90 in the total number of street crimes - i.e. a $10 \%$ decrease in the number of crimes recorded (Table 2). The number of street crimes per capita likewise showed a 9\% decrease (95\% CI 5\% to $12 \%$ decrease, $\mathrm{p}<0.001)$. The magnitude of the reduction in street crime increased with a greater length of time since LTN implementation, showing an $18 \%$ decrease after 3 years (Figure 3 ).

This favourable trend in overall street crime was driven by significant decreases in: violence and sexual offences; public order and possession of weapons; criminal damage and arson; burglary; and vehicle crime. There were also nonsignificant decreases in robbery and other theft/shoplifting (Table 2). A longitudinal study found a significant increase between 2016 and 2019 in the amount of walking done by residents of Waltham Forest LTNs (Aldred and Goodman 2020), with a point estimate of a $21 \%$ increase relative to the rest of Outer London (Supplemental Information). Given this, the decreases in violence and sexual offences, robberies, and public order crimes would be even greater on a per pedestrian basis. Conversely, given evidence that vehicle ownership in the LTNs decreased by 7\% between 2015 and 2019 (Goodman, Urban, and Aldred 2020), the observed 16\% reduction in the rate of vehicle crimes is likely to translate to a smaller reduction in risk per vehicle. 
Table 2: Association between LTN status and numbers of street crimes, Outer London 2012-2019

\begin{tabular}{|l|c|c|}
\hline & $\begin{array}{c}\text { Inside an LTN: Incidence rate ratio } \\
(95 \% \mathrm{CI}) \text { relative to the no } \\
\text { intervention control group }\end{array}$ & $\begin{array}{c}\text { Adjacent to an LTN: Incidence rate ratio } \\
(95 \% \text { CI) relative to the no intervention } \\
\text { control group }\end{array}$ \\
\hline All street crime & $0.90(0.87,0.93)^{* * *}$ & $1.00(0.97,1.02)$ \\
\hline Violence and sexual offences & $0.82(0.77,0.86)^{* * *}$ & $0.91(0.87,0.95)^{* * *}$ \\
Robbery & $0.89(0.78,1.03)$ & $0.88(0.79,0.99)^{*}$ \\
Public order and possession of weapons & $0.82(0.74,0.92)^{* * *}$ & $0.97(0.89,1.06)$ \\
Drugs & $1.08(0.95,1.22)$ & $1.25(1.13,1.37)^{* * *}$ \\
Criminal damage and arson & $0.91(0.83,1.00)^{*}$ & $0.99(0.92,1.07)$ \\
Burglary & $0.90(0.82,0.99)^{*}$ & $0.94(0.88,1.01)$ \\
Vehicle crime & $0.84(0.77,0.90)^{* * *}$ & $0.88(0.83,0.94)^{* * *}$ \\
Bicycle theft [from July 2013] & $1.85(1.52,2.26)^{* * *}$ & $1.38(1.18,1.60)^{* * *}$ \\
Other theft and shoplifting & $0.93(0.86,1.01) \dagger$ & $0.97(0.91,1.03)$ \\
Anti-social behaviour & $0.97(0.91,1.03)$ & $1.14(1.08,1.19)^{* * *}$ \\
Other street crime [from July 2013] & $1.03(0.82,1.29)$ & $0.99(0.82,1.20)$ \\
\hline
\end{tabular}

$\dagger \mathrm{p}<0.1,{ }^{*} \mathrm{p}<0.05,{ }^{* *} \mathrm{p}<0.01,{ }^{* * *} \mathrm{p}<0.001$, in tests for difference from the reference category of the 'no intervention' control area. CI=confidence interval, LTN=low traffic neighbourhood. Analysis based on 320 calendar quarters for LSOAs inside an LTN during the quarter in question, 532 quarters for LSOAs adjacent to an LTN during the quarter in question, and 98,284 quarters for LSOAs with no intervention (the reference category). The exceptions are the categories 'Bicycle theft' and 'Other street crime', which were only recorded separately from mid-2013, and which therefore have only 79,696 calendar quarters for LSOAs with no intervention. The outcome is number of street crimes, with separate regression models run for each crime outcome. All analyses use multilevel negative binomial regression and include fixed effect terms for year $(9$ categories) and calendar quarter (4 categories), and a random intercept for LSOA.

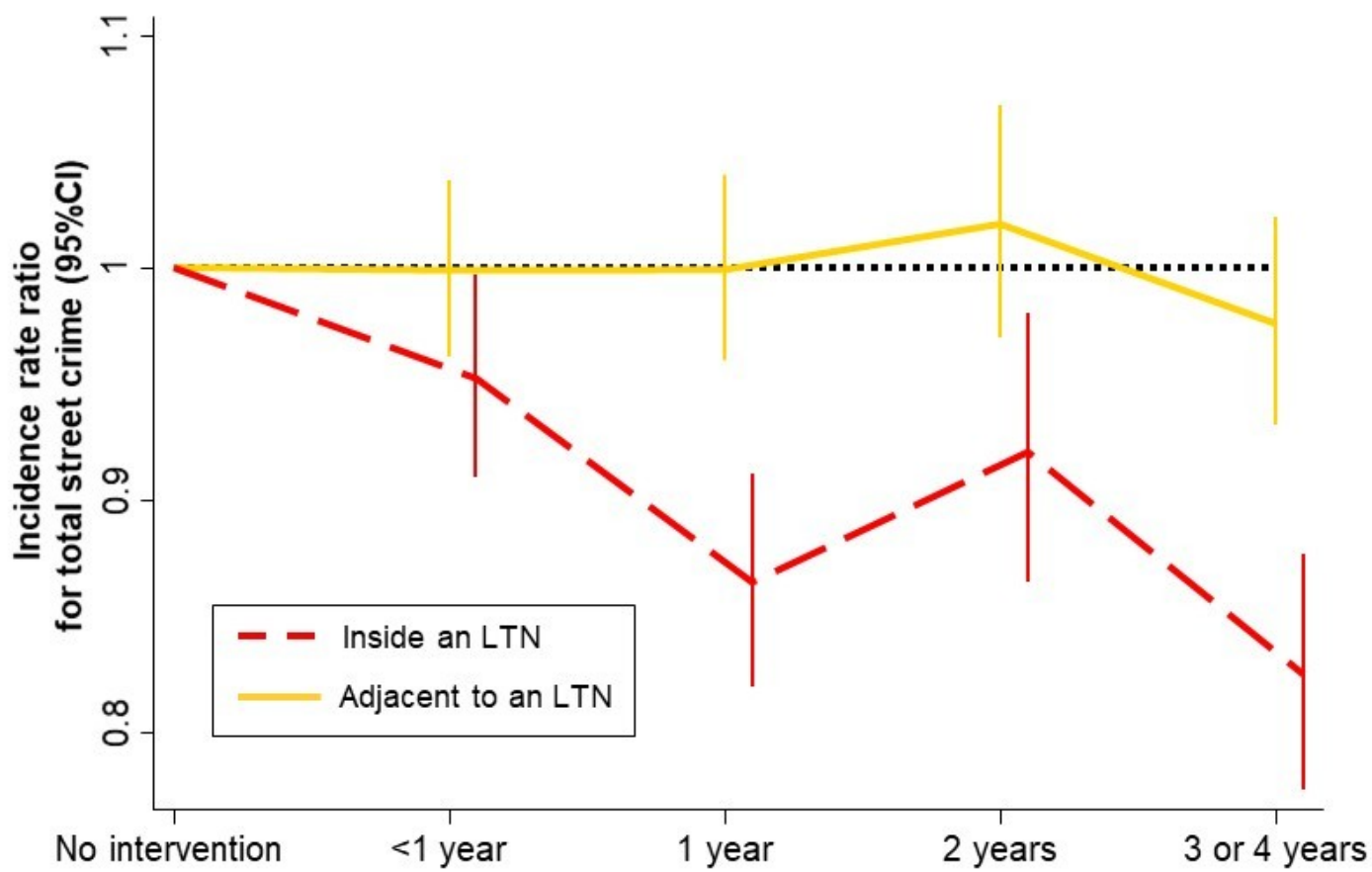

Figure 3: Incidence rate ratio for street crime by duration of LTN implementation, Outer London 2012-2019

$\mathrm{CI}=$ confidence interval, $\mathrm{LTN}=$ low traffic neighbourhood.

Bicycle theft was the only subcategory of crime that increased significantly inside the LTNs, with the rate increasing $85 \%$ (95\% CI 52\% to $126 \%$ increase) relative to the control group. A longitudinal study found a significant increase 
between 2016 and 2019 in the proportion of LTN residents reporting pastweek cycling (Aldred and Goodman 2020), with a point estimate of a 59\% increase relative to the rest of Outer London (Supplemental Information). Therefore, analogous to vehicle crime, it is likely that there is a substantially less marked increase in the number of bicycle thefts per bicycle. Note that bicycle theft represented only $1 \%$ of street crime (Table 1), hence this large relative increase was more than offset by decreases in more common crime categories like vehicle crime.

The areas adjacent to the LTNs showed a trajectory similar to the rest of Waltham Forest, and slightly better than the rest of Outer London (Figure 2). There was no subcategory of street crime that decreased significantly in the LTNs and increased significantly in the adjacent areas (Table 2). Our findings therefore did not suggest that the favourable trends inside the LTNs reflected street crime simply being displaced to surrounding areas. This accords with evidence that crime displacement typically does not occur following geographically concentrated crime reduction interventions (Johnson, Guerette, and Bowers 2014).

In conclusion, the introduction of the Waltham Forest LTNs was associated with an overall reduction of street crime, particularly more serious crimes involving direct attacks against the person. This supports previous research (Newman 1996), and adds to evidence that LTNs can create safer, more liveable neighbourhoods.

\section{ACKNOWLEDGEMENTS}

None 


\section{REFERENCES}

Aldred, Rachel, and Anna Goodman. 2020. "Low Traffic Neighbourhoods, Car Use, and Active Travel: Evidence from the People and Places Survey of Outer London Active Travel Interventions." Findings, September. https://doi.org/10.32866/001c.17128.

Cozens, P., and T. Love. 2009. "Manipulating Permeability as a Process for Controlling Crime:Balancing Security and Sustainability in Local Contexts." Special Edition of the Built Environment Journal. Security Versus Safety: How to Deliver Less Crime and More Sustainable Design 35: 346-65.

Goodman, Anna, Scott Urban, and Rachel Aldred. 2020. "The Impact of Low Traffic Neighbourhoods and Other Active Travel Interventions on Vehicle Ownership: Findings from the Outer London Mini-Holland Programme.” Findings, December. https://doi.org/10.32866/ $\underline{001 c .18200 .}$

Jacobs, J. (1961) 2000. The Death and Life of Great American Cities. London: Pimlico.

Johnson, Shane D., Rob T. Guerette, and Kate Bowers. 2014. "Crime Displacement: What We Know, What We Don't Know, and What It Means for Crime Reduction." Journal of Experimental Criminology 10 (4): 549-71. https://doi.org/10.1007/s11292-014-9209-4.

Newman, O. 1973. Defensible Space: People $\sigma^{\circ}$ Design in the Violent City. London: Architectural Press.

_- - 1996. Creating Defensible Space. Washington, DC, U.S. Department of Housing and Urban Development: Office of Policy Development and Research. 


\section{SUPPLEMENTARY MATERIALS}

\section{Supplemental Information}

Download: https://findingspress.org/article/19414-the-impact-of-introducing-a-low-trafficneighbourhood-on-street-crime-in-waltham-forest-london/attachment/51526.pdf 